\title{
Is endovascular treatment of aorto-iliac aneurysms with simultaneous unilateral revascularization of internal iliac artery by branched iliac stentgraft sufficient?
}

\author{
Petr Drac ${ }^{\mathrm{a}}$, Marie Cerna ${ }^{\mathrm{b}}$, Martin Kocher ${ }^{\mathrm{b}}$, Petr Utikala ${ }^{\mathrm{a}}$, Rohit Philip Thomas ${ }^{\mathrm{c}}$
}

\begin{abstract}
Aims. The coverage / occlusion of internal iliac artery (IIA) during endovascular treatment of aorto-iliac aneurysms (AIA) can be associated with risk of ischemic complications. To reduce these complications, unilateral or bilateral iliac branch device implantation (IBDI) has been reported. This study aims at evaluating the efficacy of simultaneous unilateral IBDI in the treatment of AIAs and comparing our results with literature.

Materials and Methods. From March 2010 to December 2019, 27 patients ( 25 men, 2 women, range 54-84 years) were treated for aorto-iliac/isolated common iliac aneurysms with simultaneous unilateral revascularization of IIA and surgical / endovascular occlusion of contralateral IIA. 27 iliac-branched devices were implanted in 27 patients. The results including ischemic complications were evaluated and compared with literature.

Results. The technical success was $100 \%$ with no perioperative mortality and morbidity of $3.7 \%$. Primary internal iliac branch patency at a median follow-up of 52 months (range 1-118 months) was $96.42 \%$. Secondary endoleak was observed in 6 patients (Type 1a [1], Type 1b [1], Type II [4]) and inflammatory complication in 1 patient. The incidence of buttock claudication one year after the procedure was $11.1 \%$. Except for buttock claudication no other ischemic complications occurred.

Conclusion. Unilateral flow preservation in the IIA territory using IBDI is associated with a lesser, but a certain risk of ischemic complications. Bilateral IBDI with bilateral flow preservation of IIAs increases the complexity, procedure -I fluoroscopy times, contrast agent volume and cost, however, may further reduce these ischemic complications.
\end{abstract}

Key words: bilateral aorto-iliac aneurysm, bilateral isolated common iliac aneurysms, endovascular treatment, iliacbranched device, internal iliac artery

Received: January 7, 2020; Revised: January 24, 2020; Accepted: January 28, 2020; Available online: February 25, 2020 https://doi.org/10.5507/bp.2020.004

(c) 2021 The Authors; https://creativecommons.org/licenses/by/4.0/

${ }^{a}$ Department of Surgery II - Vascular and Transplantation Surgery, University Hospital Olomouc and Faculty of Medicine and Dentistry, Palacky University Olomouc, Czech Republic

${ }^{b}$ Department of Radiology, University Hospital Olomouc and Faculty of Medicine and Dentistry, Palacky University Olomouc, Czech Republic 'Department of Diagnostic and Interventional Radiology, UKGM University Hospital Marburg, Philipps University, Marburg, Germany Corresponding author: Marie Cerna, e-mail: mcernam@seznam.cz

\section{INTRODUCTION}

Abdominal aortic aneurysms (AAA) are associated with the involvement of at least one common iliac artery (CIA) in approximately $18-40 \%$ of the patients ${ }^{1-6}$. Endovascular treatment of AAA extending to unilateral or bilateral common iliac bifurcations requires anchorage of the stent-graft distally to external iliac arteries (EIA), with consequent coverage/occlusion of the origin of the internal iliac arteries (IIA) to exclude the aneurysm from the circulation. The reasons for coverage/occlusion of IIA origin also include isolated CIA aneurysms extending to the common iliac bifurcation. In case of bilateral CIA aneurysms with insufficient length of the proximal and distal neck, it is necessary to implant a bifurcated type stent-graft with distal anchorage to both the EIAs. The coverage /occlusion of the IIA on one side rarely leads to serious ischemic complications ${ }^{7}$, however the need to occlude the origin of both the IIAs can be associated with higher risk of colon ischemia, buttock claudication, spinal ischemia and erectile dysfunction, although this may not necessarily occur due to rich collateral circulation. Buttock claudication and erectile dysfunction are not rare in these patients and have significant negative impact on the quality of life ${ }^{8}$. Here revascularization of the IIA, at least unilateral, may reduce the above-mentioned ischemic complications $^{9,10}$.

To prevent these ischemic complications, the treatment possibilities include either creating a surgical bypass ${ }^{11}$, or using one of the developed endovascular techniques; snorkel/chimney graft implantation, sandwich / parallel technique or iliac branch device implantation (IBDI) $\left(\right.$ ref. $^{12,13}$ ). Of these IBDI has become the most popular endovascular technique in this group of patients. The aim of this study is to evaluate our results and experience of endovascular treatment of bilateral aorto-iliac aneurysms (AIA) or bilateral isolated CIA aneurysms with simultaneous unilateral revascularization of IIA with IBDI and surgical or endovascular occlusion of the contralateral IIA to prevent ischemia in the IIA territory and compare our results with those reported in literature. 


\section{MATERIALS AND METHODS}

A retrospective analysis of a group of patients with AAA extending to both CIAs or isolated aneurysms of the both CIAs treated endovascularly with a branched stent-graft implantation for flow preservation of one of the IIAs and surgical or endovascular occlusion of the patent contralateral IIA was performed. From March 2010 to December 2019, a total of 27 such patients ( 25 men, 2 women, Mean age 71,1 years, Median age 72 years Median age men: 72 years, Median age women: 79 years) were treated endovascularly.

The morphology of the aneurysms was variable within the patient group (Table 1). In 24 patients the infrarenal aneurysm of the abdominal aorta extended to both common iliac bifurcations (Aneurysm Type IIc/2). In 1 patient with juxtarenal abdominal aortic aneurysm, the aneurysm also extended to both common iliac bifurcations (Aneurysm Type III/ IIc /2). One patient had aneurysm of both CIA extending to both common iliac bifurcations without involvement of the abdominal aorta. Another patient presented with isolated CIA aneurysms on both sides extending to common iliac bifurcations after surgical repair of the infrarenal aorta.

The different morphology of AIAs was treated as follows: 24 patients with Type IIc/2 aneurysms received a bifurcated stent-graft with anchorage of the iliac component to the EIAs and revascularization of one of the IIAs with embolization of the contralateral IIA. For one patient with type III/IIc/2, a fenestrated stent-graft of the abdominal aorta along with revascularization of one of the IIAs and embolization of the contralateral IIA was performed. For the patients with CIA aneurysms extending to both common iliac bifurcations after surgical repair of the abdominal aorta a bifurcated stent-graft with revascularization of one of the IIAs and contralateral occlusion of the other IIA was performed. The isolated CIA aneurysms without the involvement of the infrarenal aorta were treated in the similar manner.

In total, 27 IIAs were revascularized in 27 patients, with 13 on the right side and 14 on the left side. In all these 27 patients, the contralateral IIA was either embolized or surgically ligated. For embolization of IIA metal coils (Nester Coils, Cook Incorporaded, Bloomington, USA) were used in 10 patients and Amplatzer Vascular Plugs (AGA Medical Corporation, Plymouth, USA) in another 15 patients. IIA was surgically ligated in $2 \mathrm{pa}-$ tients. The etiology of the aneurysm was degenerative in all the patients.

The incidence of eventual ischemic complications in the territory of IIA in our patient group was evaluated clinically during follow-up. Questions were focused on signs of ischemic complications (buttock claudication, spinal cord claudication \& intestinal ischemia). The results were analyzed and compared with those in literature.

\section{Stent-graft}

For all the patients with type IIc aneurysms except for one, bifurcated Zenith Flex Stent-graft (Cook
Table l. Distribution of vascular morphology of aortoiliacal aneurysms in the patient group indicated for endovascular treatment with simultaneous revascularisation of internal iliac artery by branched iliacal stentgraft.

\begin{tabular}{lc}
\hline Vascular morphology of aortoiliacal aneurysms & $\mathrm{n}(\%)$ \\
\hline AAA IIc/2 & $24(88.9)$ \\
AAA III/IIc/2 & $1(3.7)$ \\
Bilateral AAIC & $2(7.4)$ \\
\hline
\end{tabular}

AAA IIc/2 - infrarenal aneurysm of the abdominal aorta extended to both common iliac bifurcations.

AAA III/ IIc/2 - juxtarenal abdominal aortic aneurysm extended to both common iliac bifurcations.

Bilateral AAIC - aneurysm of both common iliac arteries extending to both common iliac bifurcations.

Incorporated, Bloomington, USA) and branched iliac device (William Cook Australia, Ltd., Brisbane, Australia) were used. For one patient with juxtarenal AAA extending to both common iliac bifurcations, a Zenith Fenestrated AAA endovascular graft (William Cook Australia, Ltd., Brisbane, Australia) for the abdominal part and a branched iliac device as above was implanted for the pelvic part. Even for isolated CIA aneurysms where it was necessary to implant a bifurcated stent-graft with branched iliac component, a bifurcated Zenith Flex stent-graft was used. As bridging stent-graft to the IIA from branch of iliac component, self-expanding stent-graft Fluency (Angiomed GmbH \& Co, Medizintechnik KG, Karlsruhe, Germany) was used in all the patients.

\section{Procedural details}

All the procedures were performed in the hybrid OP room. First, the contralateral IIA was embolized, either with metal coils or vascular plugs, or was surgical ligated for the prevention of a type II Endoleak after stent-graft implantation. The iliac branched component was then introduced ipsilateral. The catheterization and implantation of the bridging branch stent-graft was then performed from the contralateral side across the bifurcation (Fig. 1). The planning of the stent-grafts always complied with the morphological criteria recommended by the manufacturer. Subsequently the bifurcation main body of the stent-graft and connection stent-graft to the branched iliac component was implanted. The procedure was finished with the implantation of the iliac component of the contralateral side. Only in one patient with juxtarenal aneurysm the embolization of the one of the IIAs and implantation of the fenestrated component was performed first, followed by implantation of the branched component at the end. The procedure then continued with implantation of main bifurcation body, connection stent-graft and the iliac component. Technical success was defined as successful implantation of the stent-graft without angiographic evidence of endoleak Type I or III.

The procedure was performed in spinal anesthesia in 20 patients and in general anesthesia in 7 patients. The procedure was performed with bilateral inguinal access 


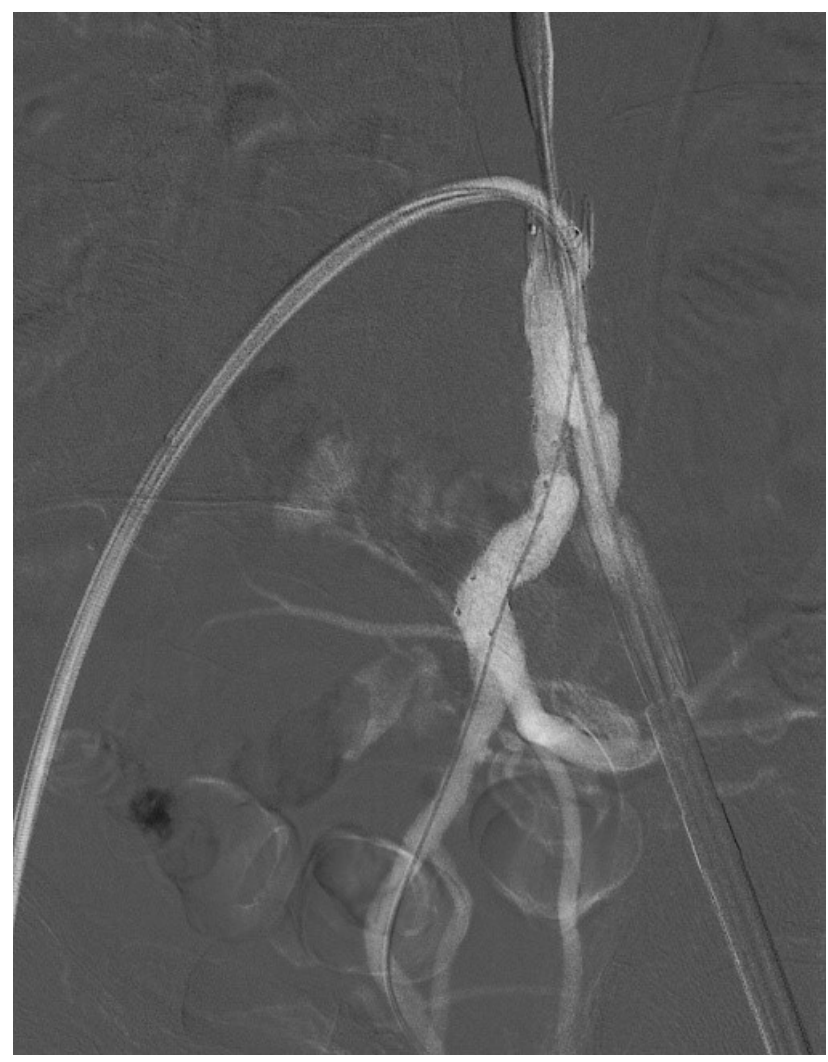

Fig. 1. DSA (Digital substraction angiography) showing the contralateral implantation of the iliac branch device across the bifurcation.

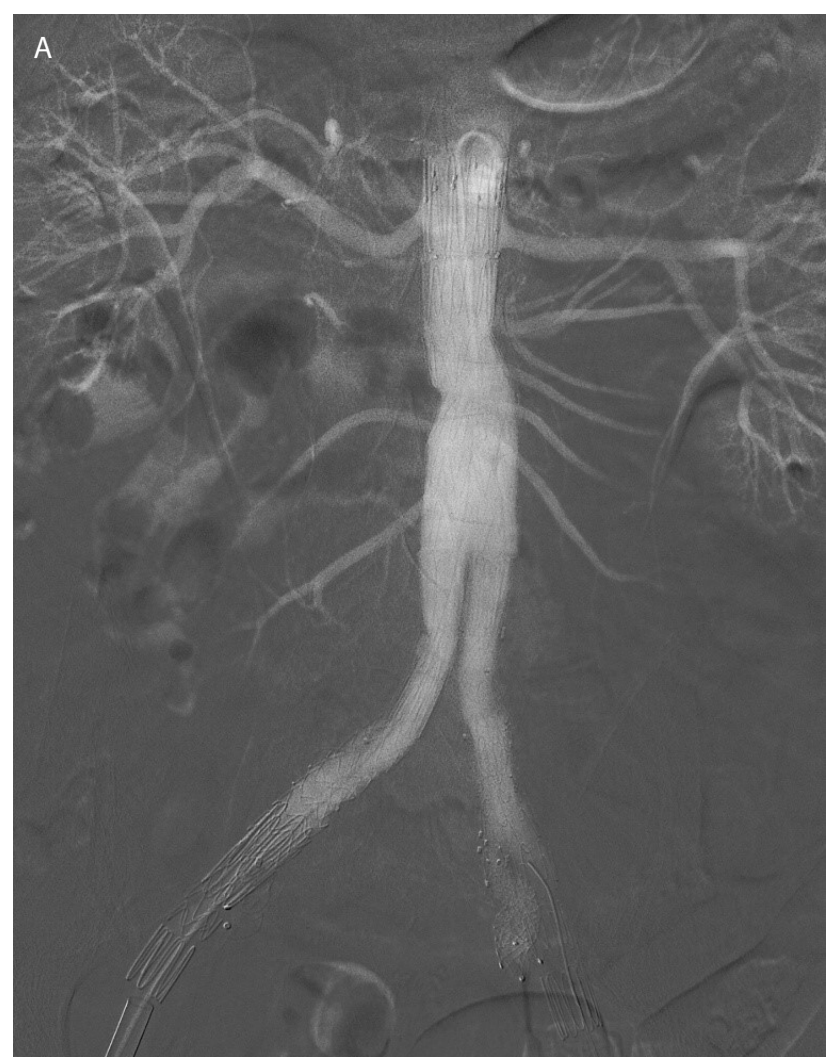

with arteriotomy in all 27 patients. All the procedures were covered with broad spectrum antibiotics and intravenous Heparin (7500 IU) during the procedure.

The follow-up protocol of the patients did not differ from that of patients after standard endovascular treatment of AAA. At the end of the procedure without the evidence of type I or III endoleak in the control angiogram (Fig. 2), a follow-up CT examination was performed after 12 months and thereafter yearly ${ }^{14}$. The patency of the iliac branch was defined as uninterrupted filling of IIA and the internal iliac branch with contrast medium. The reduction or enlargement of the aneurysm size was defined a change of size of more than $5 \mathrm{~mm}$. The clinical examination of the patients were done after a month, 6 and 12 months after the procedure and thereafter yearly.

\section{RESULTS}

The procedure was technically successful in all patients without the need of surgical conversion. The iliac branch was implanted in all patients according to the predefined plan. The primary technical success and the perioperative patency of the revasularized IIA was thus $100 \%$ in our patient group. However in 2 patients, it was necessary to reline the iliac branch created by the selfexpanding stent-graft with another balloon-expandable stents at the point of attachment to the branched compo-

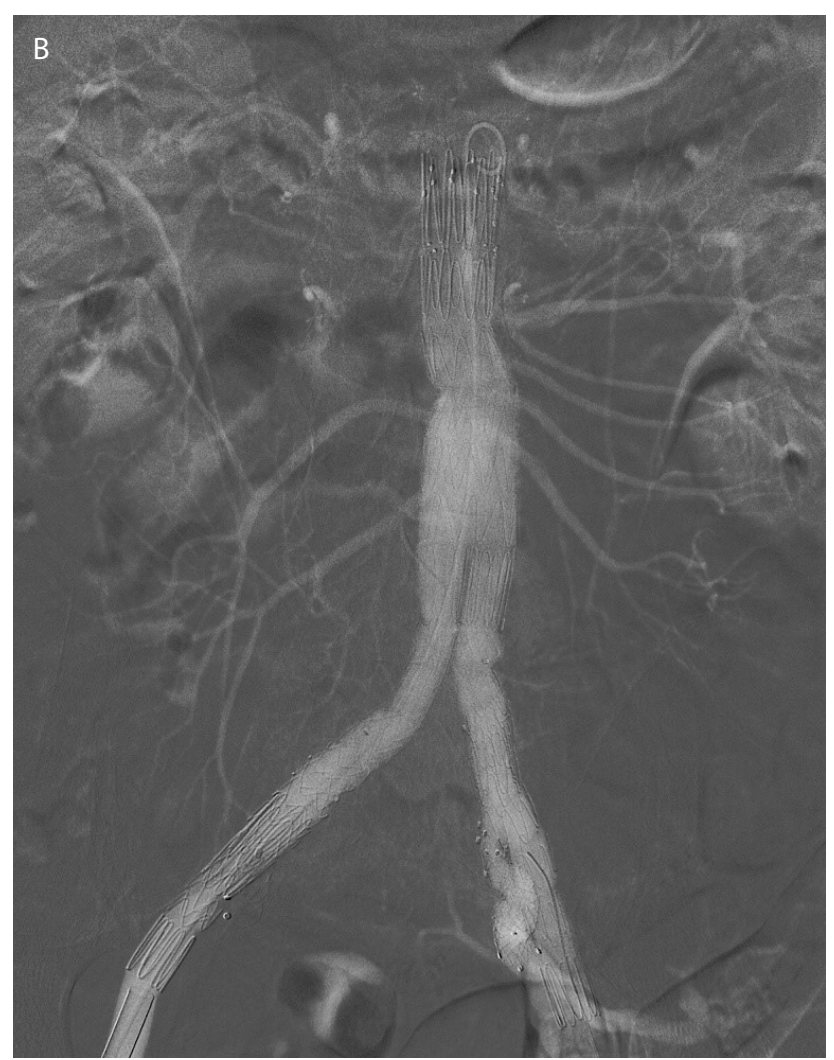

Fig. 2. DSA after the procedure showing patent renal arteries and iliac branch of stentgraft and no evidence of Type 1 or III Endoleak. 
nent because of insufficient deployment. No primary type I or III endoleak was observed.

The average duration of the procedure due to complex technical considerations was longer when compared to the classic stent-graft implantation - 156 min (range 90-225 $\mathrm{min})$. In the first 10 patients where metal coils were used for embolization of the contralateral IIA, the average procedure duration was $179 \mathrm{~min}$ (134-225 $\mathrm{min}$ ), meanwhile the average procedure time reduced to 140 min (90-215 min) where vascular plugs were used for the embolization.

No patient died within 30 days after the procedure, with a corresponding mortality of $0 \%$ in our patient group. In one of the patients, the postoperative period was complicated by repeated bleeding from the arteriotomy site with repeated revisions. No other perioperative complications were observed. Thus perioperative morbidity was $3.7 \%$. The length of hospital stay in our patient group ranged from 5 to 71 days (Mean 10.2 days, Median 8 days).

The median follow-up period in our patient group was 52 months, ranging from 1 to 118 months. 24 patients had follow-up more than one year. Two patients died during follow-up, 2 and 6 months after endovascular treatment. None of these patients died due to reasons related to the endovascular treatment. No patients were lost during the follow-up.

The primary patency of the internal iliac branch was $96.42 \%$ in the patient group. During the follow-up only one of the iliac branch showed occlusion, coincidentally in the first patient of the group, after 1 year. This resulted in buttock claudication, which still persists 9 years after occlusion of the iliac branch. Apart from the above mentioned occlusion of the iliac branch, secondary endoleak was observed in 6 patients (Type IA -1, Type IB -1 and Type II-4) as late complications. Endoleak was not detected at anchoring part of the iliac branch. In one patient, inflammatory complication was observed with sudden high temperature and elevated laboratory inflammatory markers. A PET-CT done confirmed the inflammatory infiltration in the proximal neck of the aneurysm and exclusion of other etiologies. The condition was conservatively managed with antibiotics. After 2 months the patient improved clinically with disappearance of the inflammatory findings. This patient is now followed up for 44 months and is without any further treatment and clinical complaints and complications on the follow-up CT. No migration of stent-grafts was observed and no patient required secondary late surgical conversion.

Of the 24 patients monitored for more than one year, the aneurysmal sac reduction was observed in 13 patients (54.2\%). The sac-size remained constant in 9 patients $(37.5 \%)$. An increase in the aneurysmal sac size was observed in 2 patients $(8.3 \%)$.

In one patient with increased aneurysmal sac size detected at the first follow-up CT after endovascular treatment, the observed type Ib endoleak was treated by implantation of a distal extension segment, which led to decrease in sac size on further follow-up. In the other patient with increased aneurysmal sac size two years after the procedure a type Ia endoleak was detected. The patient was treated with implantation of a proximal stent-graft extension. On follow-up the sac size remained stationary. All 4 patients with type II endoleak have a stationary aneurysmal sac size and therefore endovascular treatment is not indicated. In context of late complications, a total of 3 patients (11.1\%) were therefore treated, one was treated conservatively with antibiotics (3.7\%) and 2 patients (7.4\%) underwent endovascular re-interventions.

Except for buttock claudication, no other ischemic complications was observed in our patient group. Buttock claudication occurred in 2 patients in the early postoperative period after the procedure and is still ongoing even after IIA branch was patent. In another patient, buttock claudication occurred after the occlusion of the iliac branch in follow up 1 year later and is still ongoing. Thus the incidence of buttock claudication one year after the procedure was altogether $11.1 \%$ in our patient group.

\section{DISCUSSION}

Anchorage of iliac components to bilateral EIAs with coverage / occlusion of origin of bilateral IIA used to be the standard for endovascular treatment for type II/c abdominal aortic aneurysms and for isolated bilateral CIAs extending to iliac bifurcations. With this treatment the patients are at a risk of possible ischemic complications in the pelvic region, which may be manifested by gluteal claudication, erectile dysfunction, colon ischemia or paraplegia.

Gluteal claudication is reported to have an incidence of $35-63 \%$ after bilateral AII embolization ${ }^{12,15-18}$ postoperatively and this tends to improve and fade over time due to the development of collaterals ${ }^{19}$. However reports also exist in literature with no improvement of buttock claudication $^{5}$. Lee et al reported that no patients with buttock claudication returned to their baseline state after IIA embolization, despite significant improvement in their disability score 20 . The overall incidence of erectile dysfunction is reported to be $24 \%$, colon ischemia $3.4 \%$ and spinal cord ischemia less than $0.1 \%$ (ref. ${ }^{12}$ ). Devastating and life-threatening ischemic events (colon ischemia, spinal cord ischemia and buttock necrosis) are rare but may lead to serious or fatal complications, when they oc$\operatorname{cur}^{21-24}$. Bilateral IIA embolization leads to frequent, more severe and persistent buttock claudication and erectile dysfunction $^{25}$. Whether the IIAs occlusions are done sequentially or in one session does not affect the occurrence of complications. The number of ischemic complications in patients receiving IIA occlusion sequentially or in one session is reported not to be statistically different ${ }^{17,18}$.

All the above-mentioned literature, clearly illustrates the importance of revascularization of the IIA territory during endovascular treatment. Several treatment modalities were developed to preserve the flow in one or both the IIAs during the endovascular treatmet, thereby also avoiding the anchorage of stent-graft to the diseased CIA. Open surgical techniques including internal iliac bypass or transposition has been described in literature. Arko et 
al proved in a small series of patients a $50 \%$ incidence of early buttock claudication after IIA embolization, and a significant reduction in the incidence of buttock claudication after hypogastric bypass with a mean follow up of 15 months $^{26}$. The endovascular techniques described in literature include snorkel / chimney graft implantation, sandwich / parallel technique and reconstruction of the IIA with an IBDI. Of these IBDI has become the widely used option in the recent years.

The IBDI aims at preventing the ischemic complications by maintaining the blood supply to the complete pelvis due to its rich collateral circulation. The results of our patient group with unilateral IIA preservation demonstrates its overall efficacy in prevention of the ischemic complications ( $11.1 \%$ incidence of buttock claudication) in comparison to the occlusion of both the IIAs. No other ischemic complications were observed in our group.

The development of ischemic complications is also greatly influenced by the level of internal iliac occlusion, where the proximal occlusion at the level of its origin is associated with lesser complications than distal occlusion compromising the effective inflow to the collaterals ${ }^{15,16}$. Buttock claudication occurred in 2 patients in our group, both on the same side of IIA embolization in the early postoperative period. In both the patients the contralateral IIA was embolized with metal coils distally, although it was tried to avoid the distal embolization. The distal location of the embolization material leads to blockage of the collateral circulation and more frequent occurrence of claudication ${ }^{17,18,27}$ compared to the embolization in the proximal segment. The occlusion of the proximal segment of the IIA is practically always possible with the use of vascular plugs and the incidence of claudication is reported to be lesser with vascular plugs compared to that of metal coils ${ }^{28-30}$. In addition the use of vascular plugs also reduces the duration of the procedure and is cheaper compared with metal coils ${ }^{28-30}$. All these facts could be confirmed by our own results and experience.

The results of our study are in accordance with unilateral / bilateral IBDI reported in literature in relation to technical success (range $84-100 \%$ ), perioperative mortality (range $0-1.4 \%$ ) and perioperative morbidity (range $2-13.3 \%$ ), primary IBD patency and number of re-interventions ${ }^{8,31-35}$. The unilateral IBDI is also reported to be associated with significant lower incidence of buttock claudication and overall ischemic complications one month after the procedure in comparison to those without revascularization of IIA (ref. ${ }^{36}$ ). However here the patient group included those with IIA aneurysms and with chronic atherosclerotic IIA occlusions. In atherosclerotic occlusions the risk of incidence of ischemic complications may be decreased due to its chronic nature and presence of well-developed collateral system in comparison to acute occlusion following embolization during the procedure.

Recently studies of endovasular treatment of bilateral AIA / bilateral isolated common iliac artery anerysms with bilateral IBDI have been published ${ }^{34,35}$. These demonstrate better outcomes in relation to the prevention of ischemic complications and is reported to have similar technical sucess compared to unilateral IBDI. De Marino et al reported no early and late ischemic complications in a group of 29 patients with bilateral IBD implantation ${ }^{35}$. The group included young physically and sexually active patients with suitable anatomy and those with a previous or concomitant surgery for a thoraco-abdominal aortic aneurysm or with impaired collateral circulation to the IIA territory. Technical success was reported to be achieved in $95 \%$ (in 55 of the 58 IBDs). Similarly Maldonado et al reported only $2.5 \%$ risk of buttock claudication and no other ischemic complications in patients with bilateral common iliac artery aneurysms treated with bilateral IBDI (ref. ${ }^{34}$ ). Technical success was achieved in $97.9 \%$ (in 46 of the 47 patients). Additionally they reported that bilateral IBD implantation despite its increased procedural complexity, requires only minimally increased fluoroscopy time, procedural time and contrast material volume when compared with unilateral IBD implantation.

The current vascular guidelines provide no recommendations regarding bilateral IBDI (ref. ${ }^{37}$ ). However both the above mentioned recent studies have been published after the publication of the present guidelines and at present no comparable trials between unilateral and bilateral IBDI exist in literature. Nevertheless, promising results of bilateral IBDI with regard to reduced risk of incidence of ischemic complications may prompt to include bilateral IBDI in the endovascular treatment of AIAs with suitable anatomy in future. Further studies including randomized controlled trials could validate these results in the future.

\section{CONCLUSION}

Unilateral flow preservation in the IIA using IBDI reduces risk of ischemic complications when compared to its bilateral occlusion. Nevertheless, it is still associated with a certain risk of ischemic complications. Bilateral flow preservation of IIA with bilateral IBDI, although increases the complexity, procedure-/ fluoroscopy times, contrast agent volume and costs, may further reduce these complications.

Author contribution: PD: data collection, literature search, manuscript writing and final approval; MC: literature search, manuscript writing ; PU: literature search, critical reading; MK : critical reading, final approval; RPT: manuscript writing, literature search, English correction. Conflict of interest statement: None declared.

\section{REFERENCES}

1. Olsen PS, Schroeder T, Agerskov K, Roder O, Sorensen S, Perko M, Lorentzen JE. Surgery for abdominal aortic aneurysms. A survey of 656 patients. J Cardiovasc Surg (Torino) 1991;32:636-42.

2. Parlani G, Zannetti S, Verzini F, De Rango P, Carlini G, Lenti M, Cao P. Does the presence of an iliac aneurysm affect outcome of endoluminal AAA repair? An analysis of 336 cases. Eur J Vasc Endovasc Surg 2002;24:134-8.

3. Hobo R, Sybrandy JE, Harris PL, Buth J. Endovascular repair of abdominal aortic aneurysms with concomitant common iliac artery aneurysm: outcome analysis of the EUROSTAR experience. J Endovasc Ther 2008;15:12-22. 
4. Torsello G, Schönefeld E, Osada N, Austermann M, Pennekamp C, Donas KP. Endovascular treatment of common iliac artery aneurysms using the bell-bottom technique: long-term results J Endovasc Ther 2010;17:504-9.

5. Lee WA, Nelson PR, Berceli SA, Seeger JM, Huber TS. Outcome after hypogastric artery bypass and embolization during endovascular aneurysm repair J Vasc Surg 2006;44:1162-8.

6. Karthikesalingam A, Hinchliffe RJ, Holt PJ, Boyle JR, Loftus IM, Thompson MM. Endovascular aneurysm repair with preservation of the internal iliac artery using the iliac branch graft device Eur J Vasc Endovasc Surg 2010;39:285-94.

7. Karch LA, Hodgson KJ, Mattos MA, Bohannon WT, Ramsey DE, McLafferty RB. Adverse consequences of internal iliac artery occlusion during endovascular repair of abdominal aortic aneurysm. J Vasc Surg 2000;32:676-83.

8. Kouvelos GN, Katsargyris A, Antoniou GA, Oikonomou K, Verhoeven EL. Outcome after interruption or preservation of internal iliac artery flow during endovascular repair of abdominal aorto-iliac aneurysms. Eur J Vasc Endovasc Surg 2016;52:621-34.

9. Ziegler P, Avgerinos ED, Umscheid T, Perdikides T, Erz K, Stelter WJ. Branched iliac bifurcation: 6 years experience with endovascular preservation of internal iliac artery flow. J Vasc Surg 2007;46:204-10.

10. Yano OJ, Morrissey N, Eisen L, Faries PL, Soundararajan K, Wan S, Teodorescu V, Kerstein M, Hollier LH, Marin ML. Intentional internal iliac artery occlusion to facilitate endovascular repair of aortoiliac aneurysms. J Vasc Surg 2001;34:204-11.

11. Mansukhani NA, Havelka GE, Helenowski IB, Rodrigez HE, Hoel AW Eskandari MK. Hybrid EVAR : preservation of pelvic perfusion with external to internal iliac artery bypass Ann Vasc Surg 2017;42:162-8.

12. Lin $\mathrm{PH}, \mathrm{Chen} A Y, \mathrm{Vij} A$. Hypogastric artery preservation during endovascular aortic aneurysm repair: Is it important? Semin Vasc Surg 2009;22:193-200.

13. Duvnjak S. Endovascular treatment of aortoiliac aneurysms: From intentional occlusion of the internal iliac artery to branch iliac stent graft. World J Radiol 2016;8:275-80.

14. Černá $M$, Köcher $M$, Utíkal $P$, Benýšek V, Bučil J, Heřman $M$, Bachleda P, Koutná J. Úprava protokolu sledování nemocných po endovaskulární léčbě aneuryzmatu abdominální aorty na základě retrospektivní analýzy vývoje velikosti vaku aneuryzmatu a výskytu endoleaků. Čes Radiol 2005;59(3):153-60. (In Czech)

15. Zander T, Baldi S, Rabellino M, Rostagno R, Isaza B, Llorens R, Carreira JM, Maynar M.. Bilateral hypogastric artery occlusion in endovascular repair of abdominal aortic aneurysms and its clinical significance. J Vasc Interv Radiol 2007;18:1481-6.

16. Rayt HS, Bown MJ, Lambert KV, Fishwick NG, McCarthy MJ, London NJ, Sayers RD. Buttock claudication and erectile dysfunction after internal iliac artery embolization in patients prior to endovascular aortic aneurysm repair. Cardiovasc Intervent Radiol 2008;31:728-34.

17. Bartby MJ, Munneke GM, Belli AM, Loosemore TM, Loftus I, Thompsin MM, Morgan RA. How safe is bilateral internal iliac artery embolization prior to EVAR? Cardiovasc Intervent Radiol 2008;31:246-53.

18. Chun JY, Mailli L, Abbasi MA, Belli AM, Gonsalves M, Munneke G, Ratnam L, Loftus IM, Morgan R. Embolization of the internal iliac artery before EVAR: Is it effective? Is it safe? Which technique should be used? Cardiovasc Intervent Radiol 2014;37:32-6.

19. Farahmand $P$, Becquemin JP, Desgranges $P$, Allaire E., Marzelle J Roudot-Thoraval F. Is hypogastric artery embolization during endovascular aortoiliac aneurysm repair (EVAR) innocuous and useful? Eur J Vasc Endovasc Surg 2008;35:429-35.

20. Lee WA, O'Dorisio J, Wolf YG, Hill BB, Fogarty TJ, Zarins CK. Outcome after unilateral hypogastric artery occlusion during endovascular aneurysm repair. J Vasc Surg 2001;33:921-6.

21. Schoder M, Zaunbauer L, Holzeinbein T, Fleischmann D, Cejna M Kretschmer G. Internal iliac artery embolization before endovascular repair of abdominal aortic aneurysms : frequency, efficiacy, and clinical results. AJR Am J Roentgenol 2001;11:573-7.
22. Mehta M, Veith FJ, Darling RC, Roddy SP, Ohki T, Lipsitz EC, Paty PS, Kreienberg PB, Ozsvath KJ, Chang BB, Shah DM. Effects of bilateral hypogastric artery interruption during endovascular and open aortoiliac aneurysm repair. J Vas Surg 2004;40:698-702.

23. Lin PH, Bush RL, Lumsden AB. Sloughing of the scrotal skin and impotence subsequent to bilateral hypogastric artery embolization for endovascular aortoiliac aneurysm repair. JVasc Surg 2001;34:748-50.

24. Wolpert LM, Dittrich KP, Hallisey MJ, Allmendiger PP, Gallagher JJ, Heydt K, Lowe R, Windels M, Drezner AD. Hypogastric artery embolization in endovascular abdominal aortic aneurysm repair. J Vasc Surg 2001;33:1193-8.

25. Jean - Baptiste E, Brizzi S, Bartoli MA, Sadaghianloo N, Baque J. Magnan PE, Hassen-Khodja R. Pelvic ischemia and quality of life scores after interventional occlusion of the hypogastric artery in patients undergoing endovascular aortic aneurysm repair. J Vasc Surg 2014;60:40-9.

26. Arko FR, Lee WA, Hill BB, Fogarty TJ, Zarins CK. Hypogastric artery bypass to preserve pelvic circulation: improved outcome after endovascular abdominal aortic aneurysm repair. J Vasc Surg 2004;39:4048 .

27. Kritpracha B, Pigott JP, Price $\mathrm{Cl}$, Russell TE, Corbey MJ, Beebe HG Distal internal iliac artery embolization: a procedure to avoid. J Vasc Surg 2003;37:943-8.

28. Vandy F, Criado E, Upchurch GR Jr, Williams DM, Rectenwald J, Eliason J. Transluminal hypogastric artery occlusion with an Amplatzer vascular plug during endovascular aortic aneurysm repair. J Vasc Surg 2008:48:1121-4.

29. Ryer EJ, Garvin RP, Webb TP, Franklin DP, Elmore JR. Comparison of outcome with coils versus vascular plug embolization of the internal iliac artery for endovascular aortoiliac aneurysm repair. J Vasc Surg 2012;56:1239-45.

30. Libicher M, Pavlidis D, Bangard C, Gawenda M. Occlusion of the internal iliac artery prior EVAR: comparison of coils and plugs. Vasc Endovasc Surg 2012;46:34-9.

31. Parlani G, Verzini F, De Rango P, Brambilla D, Coscarella C, Ferrer C, Cao P. Long-term results of iliac aneurysm repair with iliac branched endograft: a 5-year experience on 100 consecutive cases. Eur J Vasc Endovasc Surg 2012;43:287-92.

32. Pratesi G, Fargion A, Pulli R, Barbante M, Dorigo W, Ippoliti A, Pratesi C. Endovascular treatment of aorto-iliac aneurysms: four-year results of iliac branch endograft. Eur J Vasc Endovasc Surg 2013;45:607-9.

33. Wong S, Greenberg RK, Brown CR, Mastracci TM, Bena J, Eagleton MJ. Endovascular repair of aortoiliac aneurysmal disease with the helical iliac bifurcation device and the bifurcated-bifurcated iliac bifurcation device. J Vasc Surg 2013;58:861-9.

34. Maldonado TS, Mosquera NJ, Lin P, Bellosta R, Barfield M, Moussa A, Rhee R, Schermerhorn ML, Weinberger J, Wikkeling M, Heyligers J, Veith FJ, Milner R, Reijnen MPJ; Gore Bilateral IBE Study Group. Gore Iliac branch endoprosthesis for treatment of bilateral common iliac artery aneurysms. J Vasc Surg 2018;68:100-8.

35. de Marino PM, Botos B, Kouvelos G, Verhoeven E. L.G., Katsargyris A. Use of Bilateral Cook Zenith Iliac Branch Devices to Preserve Internal Iliac Artery Flow During Endovascular Aneurysm Repair Eur J Vasc Endovasc Surg 2019;57:213-9.

36. Kocher M, Utíkal P, Černá M, Bachleda P, Dráč P, Prášil V, Zapletalová J. Endovaskulární léčba aortouniiliakálních aneurysmat se současnou revaskularizací povodí vnitřní iliakální tepny použitím větveného iliakálního stentgraftu Ces Radiol 2018;72(2):76-83. (In Czech)

37. Chaik of E.L, Dalman RL, Eskandari MK, Jackson BM, Lee WA, Mansour MA, Mastracci TM, Mell M, Murad MH, Nguyen LL, Oderich GS, Patel MS, Schermerhorn ML, Starnes BW. The Society for Vascular Surgery practice guideliens on the care of patients with an abdominal aortic aneurysm. J Vasc Surg 2018;67:2-77. 